\title{
High-Gain and Wide-Band Single-Layer Patch Antenna for Wireless Communications
}

\author{
Chi-Lun Mak, Member, IEEE, Hang Wong, Member, IEEE, and Kwai-Man Luk, Fellow, IEEE
}

\begin{abstract}
A technique employing the use of parallel feeds is applied to the recently proposed $L$-probe coupled patch antenna design. By employing only two $L$-probes, with proper separation, for feeding one single patch, a twin- $L$-probe coupled patch antenna is designed with both high-gain $(10 \mathrm{dBi})$ and wide-band $[25 \%$, standing wave radio $(\mathrm{SWR}) \leq 1.5]$ characteristics. In addition, the 1-dB-gain bandwidth is around $26 \%$, which covers the impedance bandwidth. Furthermore, a noticeable suppression of cross-polarization radiation is observed. Simulation results are in good agreement with those noteworthy characteristics obtained from experiments. The proposed antenna is suitable for modern mobile communication applications.
\end{abstract}

Index Terms-High-gain antenna, $L$-probe, low cross-polarization, wide-band antenna.

\section{INTRODUCTION}

I $\mathrm{T}$ IS well known that patch antennas offer many advantages, such as low profile, light weight, conformability, etc. However, conventional patch antennas have major weaknesses of narrow bandwidth and low gain [1]. Generally, both the bandwidth and gain will increase with substrate thickness (up to certain limit), but decrease with increasing dielectric constant [2], [3]. Indeed, there are many different methods proposed in the literature to tackle the narrow-bandwidth problem [4]-[12] or the low-gain limitation [13]-[16], but not for both weaknesses together. Furthermore, a low-profile single patch antenna, which is simultaneously high in gain and wide in bandwidth, does not appear to be available yet.

One common method for bandwidth enhancement is using parasitic patches, either in co-planar [5]-[7] or stacked geometry [8], and such a design can yield a bandwidth up to around 25\% [standing wave radio $(\mathrm{SWR}) \leq 2$ ]. However, no noticeable improvement in gain was seen. On the other hand, although the gain can be improved to around $10 \mathrm{dBi}$ (estimated) [15] by enlarging the separation between the driven patch and the stacked parasitic patch to approximate $0.3 \lambda$, the tradeoff is narrow in bandwidth, around $2 \%-3 \%$. The gain can also be increased in co-planar geometry by placing the parasitic patches adjacent to the fed patch to form an array [16], but its gain bandwidth is not wide enough for most applications. Besides, the major disadvantage of using parasitic elements is an unfavorably large antenna size.

Manuscript received November 27, 2003; revised June 8, 2004 and September 11, 2004. The work of K.-M. Luk was supported by The Croucher Foundation, Hong Kong, through a Croucher Senior Research Fellowship. The review of this paper was coordinated by Dr. R. Janaswamy.

The authors are with the Department of Electronic Engineering, City University of Hong Kong, Kowloon, Hong Kong (e-mail: clmak@ieee.org; hangwong@ieee.org; eekmluk@cityu.edu.hk).

Digital Object Identifier 10.1109/TVT.2004.838899
Another popular method for bandwidth enhancement is by employing a coaxial probe to feed a slotted patch on an electrically thick substrate $(0.08-0.1 \lambda)$ of low dielectric constant [9], [10]. The achievable bandwidth can be $30 \%$ (SWR $\leq 2$ ) with a gain around 6-8 $\mathrm{dBi}$ within the operating bandwidth.

In this paper, based on the idea of using parallel feeds [17], we propose a simple twin-feed structure with two inphased $L$-probes [11] to further enhance the gain to $10 \mathrm{dBi}$ while maintaining the wide-band performance. In addition, the achieved 1-dB-gain-bandwidth is also wide enough to cover the operating bandwidth. Both measurement and simulation results will be presented.

\section{Twin $L$-Probe Coupled Patch Antenna}

The idea of the proposed feed structure is designated as a twinfeed design. A prototype designed at $f=5 \mathrm{GHz}$, with two inphased $L$-probes, is fabricated as shown in Fig. 1. A copper patch has thickness of $0.3 \mathrm{~mm}(0.005 \lambda)$, width $W=44 \mathrm{~mm}(0.733 \lambda)$, and length $L=22 \mathrm{~mm}(0.367 \lambda)$. The aspect ratio $W / L$ of the patch is equal to 2.0. The patch is supported by two small cubic foam spacers $\left(\varepsilon_{r} \cong 1\right)$ of thickness $H=6 \mathrm{~mm}(0.1 \lambda)$. The fundamental mode $\left(\mathrm{TM}_{01}\right)$ of the patch is simultaneously excited by the two inphased $L$-shaped probes (with probe radius $=0.5 \mathrm{~mm}$ ), which are separated by $S=28.6 \mathrm{~mm}(0.477 \lambda)$ and connected to the microstrip feed network mounted on the other side of the ground plane. The simple T-shaped power divider is etched on a Duriod substrate with $\varepsilon_{r}=2.33$ and thickness of $1.5748 \mathrm{~mm}(0.062 \mathrm{in})$. The square ground plane has side length of $100 \mathrm{~mm}(1.667 \lambda)$. The two $L$-shaped probes have the same size of vertical arm $a=4.5 \mathrm{~mm}(0.075 \lambda)$ and horizontal arm $b=12$ $\mathrm{mm}(0.2 \lambda)$. From Fig. 1(b), they have zero inset distance (i.e., $d=0$ ) with respect to the patch. The characteristic impedance of the feed line are $Z_{0}=50 \Omega$ and $Z_{1}=100 \Omega$, with line width of 4.877 and $1.41 \mathrm{~mm}$, respectively. A SubMiniature Version A (SMA) launcher is connected to the end of the feed line.

\section{Measurement and Simulation Results}

\section{A. Experiments}

In order to demonstrate the effectiveness of the proposed twin-feed design, another prototype is fabricated for comparison, which is identical to the proposed antenna except that only one $L$-probe is used instead. With zero inset distance $(d=0)$ again, the arm lengths of this single $L$-probe are slightly adjusted ( $a=3.5 \mathrm{~mm}$ and $b=8 \mathrm{~mm}$ ) for the best impedance matching. The performances of the two prototypes are measured by an HP8510-C Network Analyzer, a compact range with ORBIT/FR MiDAS Far-Field Antenna Measurement and 


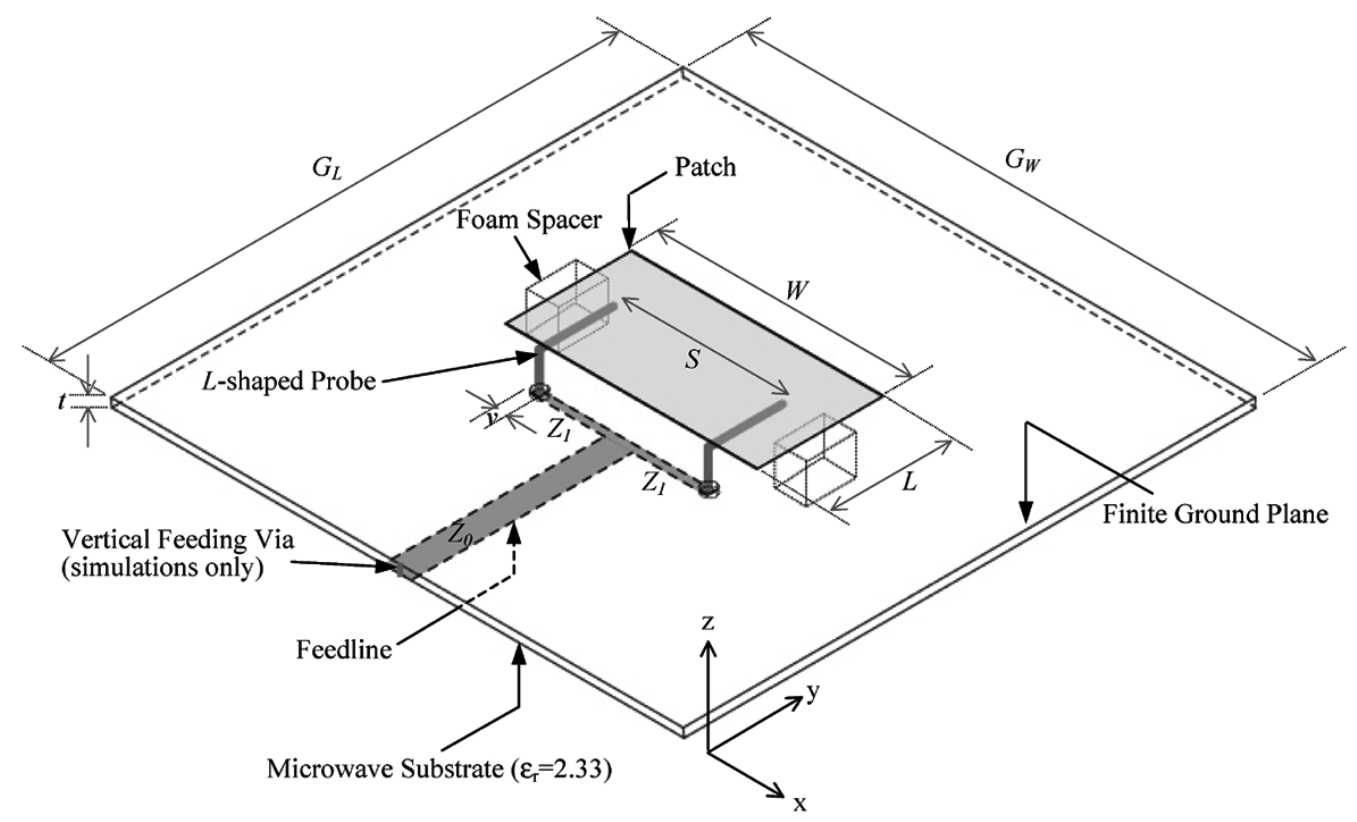

(a)

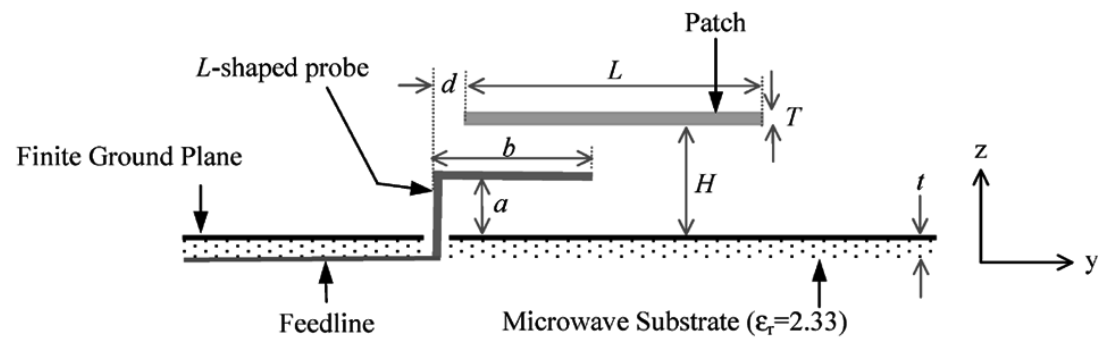

\begin{tabular}{|c|c|c|c|c|c|c|c|c|c|c|c|c|}
\hline Parameters & $L$ & $H$ & $W$ & $T$ & $a$ & $b$ & $v$ & $d$ & $S$ & $t$ & $G_{L}$ & $G_{W}$ \\
\hline Value / $\mathrm{mm}$ & $\left(\begin{array}{c}22 \\
(0.367 \lambda)\end{array}\right.$ & $\begin{array}{c}6 \\
(0.1 \lambda)\end{array}$ & $\begin{array}{c}44 \\
(0.733 \lambda)\end{array}$ & $\begin{array}{c}0.3 \\
(0.005 \lambda)\end{array}$ & $\begin{array}{c}4.5 \\
(0.075 \lambda)\end{array}$ & $\begin{array}{c}12 \\
(0.2 \lambda)\end{array}$ & $\begin{array}{c}2 \\
(0.033 \lambda)\end{array}$ & $\begin{array}{c}0 \\
(0 \lambda)\end{array}$ & $\begin{array}{c}28.6 \\
(0.477 \lambda)\end{array}$ & $\begin{array}{c}1.5748 \\
(0.026 \lambda)\end{array}$ & $\begin{array}{c}100 \\
(1.667 \lambda)\end{array}$ & $\begin{array}{c}100 \\
(1.667 \lambda)\end{array}$ \\
\hline
\end{tabular}

(b)

Fig. 1. Geometry of twin- $L$-probe coupled patch antenna. (a) Perspective and (b) side views.

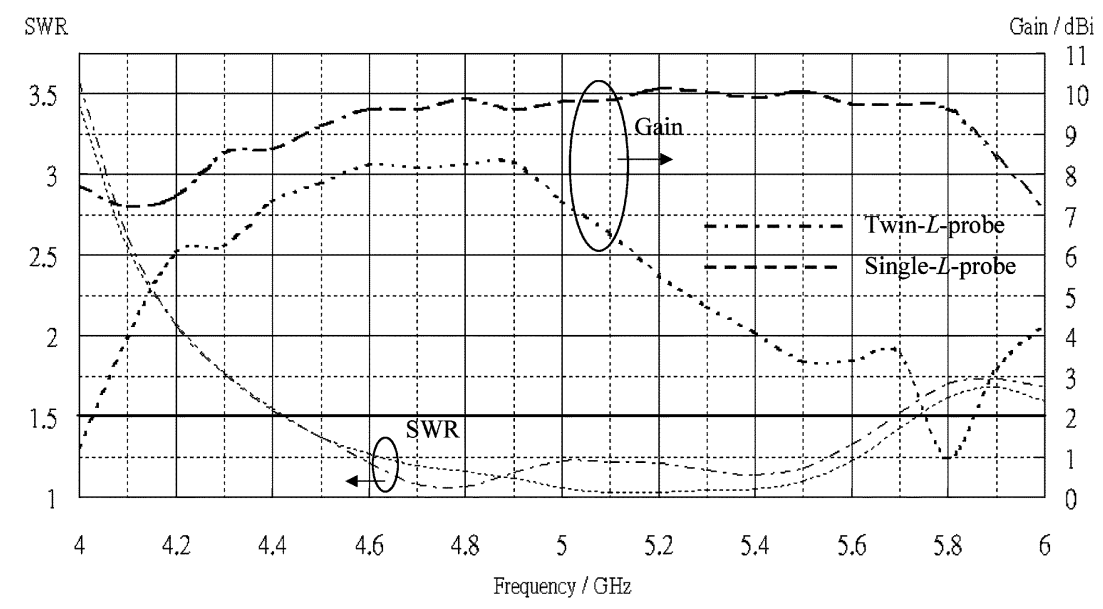

Fig. 2. Measured results of SWR and gain of both prototypes.

Analysis System (Horsham, PA). As for the gain measurement, a NARDA-643 standard gain horn is used.

Fig. 2 shows comparisons of the measured results of gain and SWR of both prototypes. As seen from the SWR curves, both antennas have wide impedance bandwidth of $25 \%$ (SWR $\leq 1.5$ ) from 4.42 to $5.7 \mathrm{GHz}$. From the gain curves, it is obvious to see that the proposed antenna has a better gain of $10 \mathrm{dBi}$, which is stable across the operating bandwidth with 
TABLE I

Comparisons of the MEASUREd Results BetweEn the Two Prototypes

\begin{tabular}{c|c|c|c|c|c}
\hline Measurements & Bandwidth (SWR $\leq 1.5)$ & \multirow{2}{*}{$\begin{array}{l}\text { Max. } \\
\text { Gain }\end{array}$} & $1 \mathrm{~dB}$-Gain-Bandwidth & \multicolumn{2}{|c|}{$3 \mathrm{~dB}-$ Beamwidth } \\
& & & $\mathrm{H}$ & $\mathrm{E}$ \\
\hline Single $L$-probe coupled patch & $25.81 \%(4.42-5.73 \mathrm{GHz})$ & $8 \mathrm{dBi}$ & $14.21 \%(4.38-5.05 \mathrm{GHz})$ & & \\
\hline Twin $L$-probe coupled patch & $24.12 \%(4.42-5.69 \mathrm{GHz})$ & $10 \mathrm{dBi}$ & $26.74 \%(4.47-5.85 \mathrm{GHz})$ & & $66^{\circ}$ \\
\hline
\end{tabular}
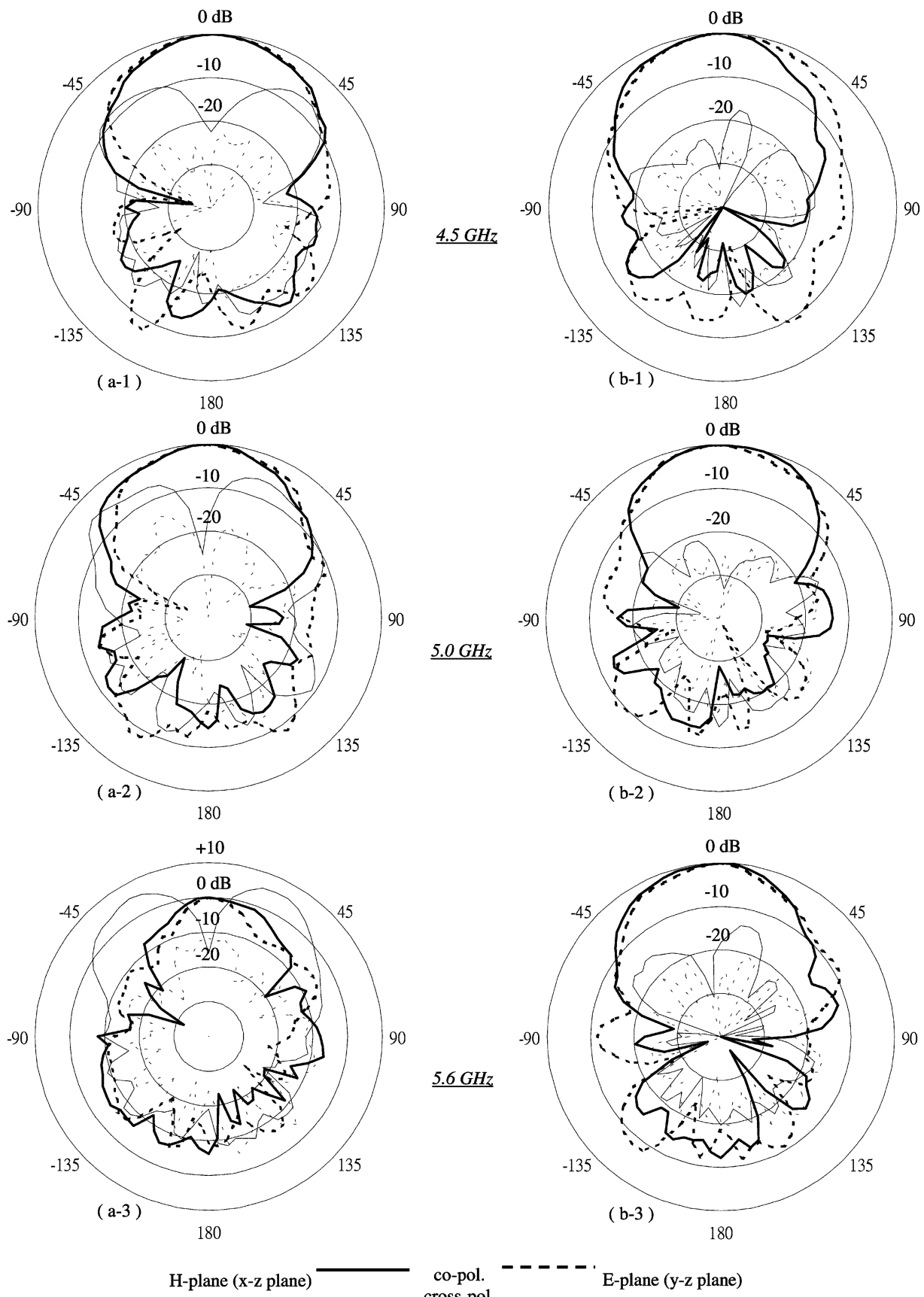

H-plane (x-z plane) cross-pol.

Fig. 3. Measured radiation patterns at 4.5,5.0, and $5.6 \mathrm{GHz}$ of (a) the single- $L$-probe coupled patch antenna and (b) the twin- $L$-probe coupled patch antenna.

1-dB-gain bandwidth of $26 \%$. Comparing with the maximum gain of the single- $L$-probe coupled patch of $8 \mathrm{dBi}$, there is an about $2.0-\mathrm{dB}$ improvement. The improvement is much more significant at the upper region, $5-5.7 \mathrm{GHz}$, of the operating band, an approximately 3-6-dB difference in gain is observed. The increase in gain is mainly due to the effective suppression of cross-polar radiation. The measured results are tabulated in Table I. 


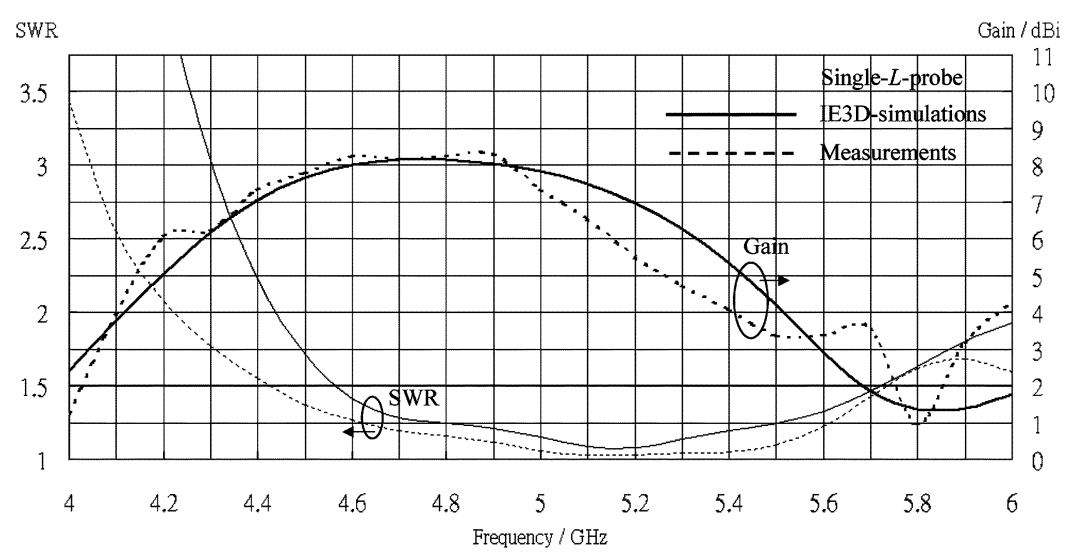

Fig. 4. Simulated and measured results of SWR and gain of the single- $L$-probe coupled patch.

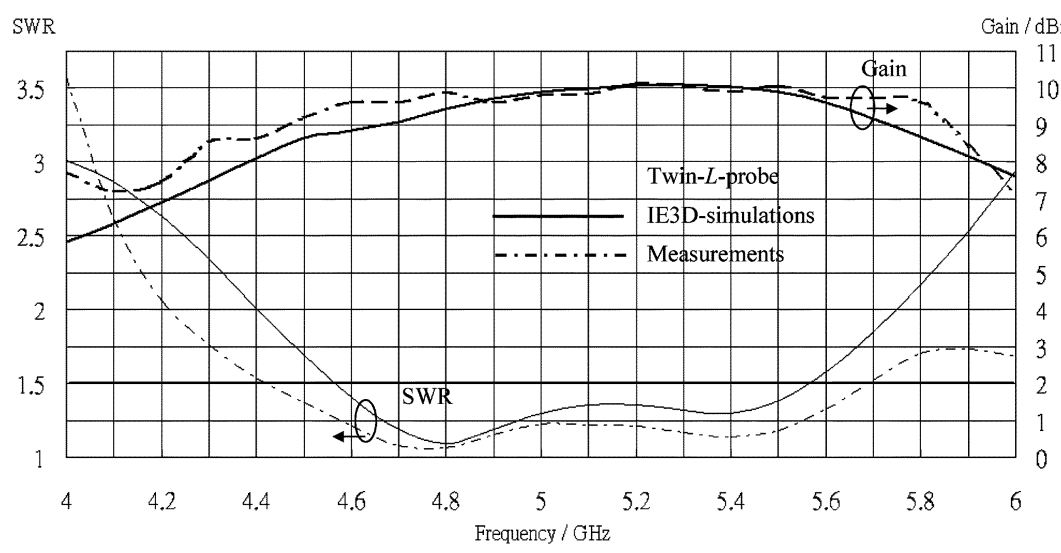

Fig. 5. Simulated and measured results of SWR and gain of the twin- $L$-probe coupled patch.

TABLE II

Comparisons of the Simulated Results Between the Two Prototypes

\begin{tabular}{|c|c|c|c|c|c|}
\hline \multirow{2}{*}{ Simulations } & \multirow{2}{*}{ Bandwidth $(\mathrm{SWR} \leq 1.5$ ) } & \multirow{2}{*}{$\begin{array}{l}\text { Max. } \\
\text { Gain }\end{array}$} & \multirow{2}{*}{ 1dB-Gain-Bandwidth } & \multicolumn{2}{|c|}{$3 \mathrm{~dB}-$ Beamwidth } \\
\hline & & & & $\mathrm{H}$ & $\mathrm{E}$ \\
\hline Single $L$-probe coupled patch & $22.74 \%(4.56-5.73 \mathrm{GHz})$ & $8 \mathrm{dBi}$ & $16.67 \%(4.40-5.20 \mathrm{GHz})$ & \multirow{2}{*}{$60^{\circ}$} & \multirow{2}{*}{$66^{\circ}$} \\
\hline Twin $L$-probe coupled patch & $19.76 \%(4.56-5.56 \mathrm{GHz})$ & $10 \mathrm{dBi}$ & $20.17 \%(4.68-5.73 \mathrm{GHz})$ & & \\
\hline
\end{tabular}

As for the comparisons of radiation patterns, Fig. 3 shows the measured results at $4.5,5.0$, and $5.6 \mathrm{GHz}$ for both antennas. In Fig. 3(a), the cross-polar level in the $H$-plane of the single- $L$-probe coupled patch is relatively high, especially at $5.6 \mathrm{GHz}$ (upper band), where the cross-polar level is higher than the co-polar level. The higher cross-polar radiation is due to a stronger high-order mode radiation at a higher frequency and unwanted radiation from the vertical arm. In contrast, in Fig. 3(b), the cross-polar radiation of the proposed antenna is significantly suppressed, around $-17 \mathrm{~dB}$ across the entire operating bandwidth. For both antennas, the broadside patterns are stable across the operating bandwidth and the beamwidth at the $H$-plane is around $56^{\circ}$ on average, which is slightly narrower than that at the $E$-plane of approximately $60^{\circ}$. Such phenomenon coincide with that obtained by simulations, which will be presented as follows.

\section{B. Simulations}

Simulation studies are performed using a commercial method-of-moments (MoM)-based electromagnetic (EM) simulator-Zeland-IE3D (Zeland Software, Inc., Fremont, CA). A very short vertical feeding via has been employed for feed excitation instead of using the edge-feed method, as shown in Fig. 1(a), due to the inaccuracy of IE3D in modeling edge feed in a structure having finite ground plane. Figs. 4 and 5 show the comparisons between the simulated and measured results (SWR and gain) for both antennas and good agreements are observed. The simulation results are tabulated in Table II. Most importantly, the simulation confirms that the gain can be increased by using the proposed twin-feed design and, at the same time, maintain a wide-band performance. Moreover, Fig. 5 also verifies the wide gain-bandwidth feature. 

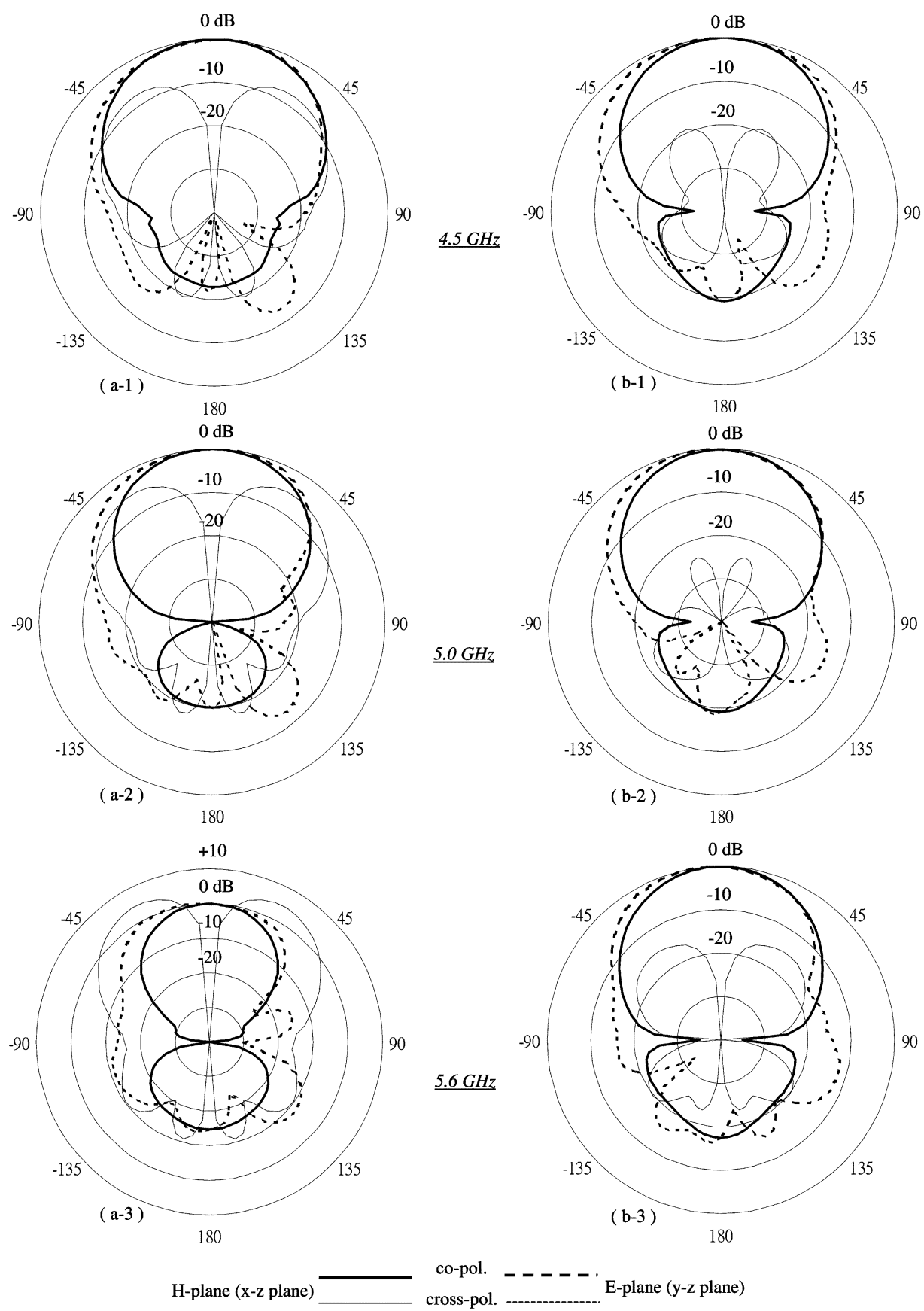

Fig. 6. Simulated radiation patterns at $4.5,5.0$, and $5.6 \mathrm{GHz}$ of (a) the single- $L$-probe fed patch antenna and (b) the twin- $L$-probe coupled patch antenna.

Fig. 6 presents simulated radiation patterns of both antennas at 4.5, 5.0, and 5.6 GHz. In comparison with the measured patterns, as shown in Fig. 3, good agreements are observed again, especially the stable and quite symmetric patterns at both principle planes across the operating bandwidth. In addition, the simulated patterns verify the beamwidth at the $H$-plane is slightly narrower than that at the $E$-plane. Furthermore, in Figs. 3(b) and 6(b), the simulation verifies that the cross-polar level in the $H$-plane is suppressed significantly by the proposed design.

\section{Parametric Studies}

In order to investigate the effects of various parameters on the performance of the proposed antenna, especially the aspect ratio $W / L$ and the probe-to-probe separation $S$, we have performed parametric studies using the IE3D simulator, which are believed to be efficient and convenient. Throughout the studies, infinite ground-plane, air-substrate, zero-thickness metallic layers are assumed for relatively fast computations. Therefore, there are bit differences in simulation models when compared with that used for the actual antenna (Fig. 1), as discussed in Section III-B. Another discrepancy is that the feed line on the air substrate is now located on the same side as the patch, above the infinite ground plane. At this moment, edge feed can be employed in the simulations, since infinite ground plane is being used. The obtained results are useful in providing design guideline for antenna designers. Throughout the simulation studies, two parameters are kept constant, which 


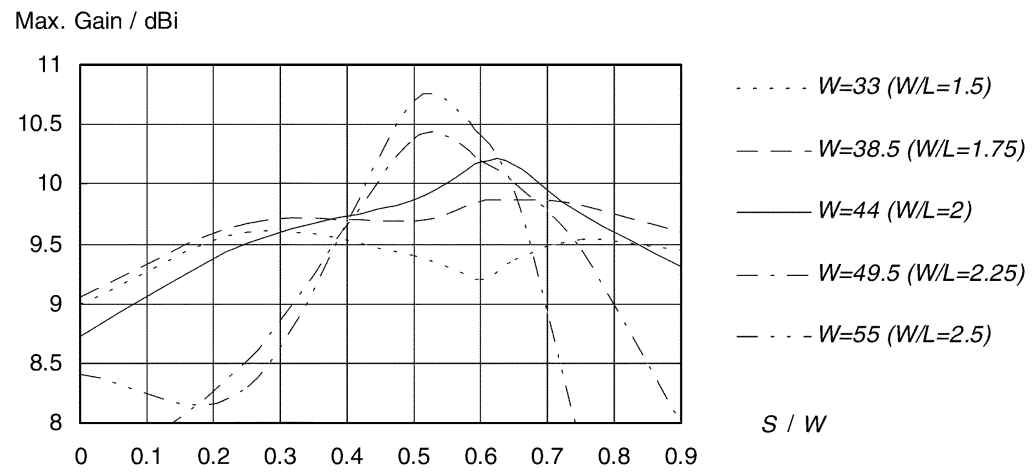

Fig. 7. Parametric studies: simulated results of maximum gain versus $S / W$.

TABLE III

Parametric Studies: Summary of the Simulated Gain of the Proposed Design With Different Patch Widths

\begin{tabular}{c|c|c|c|c|c}
\hline $\mathrm{W} / M M$ & 33 & 38.5 & 44 & 49.5 & 55 \\
\hline$\left(\frac{W}{L}\right)$ & $(1.5)$ & $(1.75)$ & $(2.0)$ & $(2.25)$ & $(2.5)$ \\
\hline Max. Gain/dBi & 9.6 & 9.87 & 10.2 & 10.38 & 10.69 \\
\hline
\end{tabular}

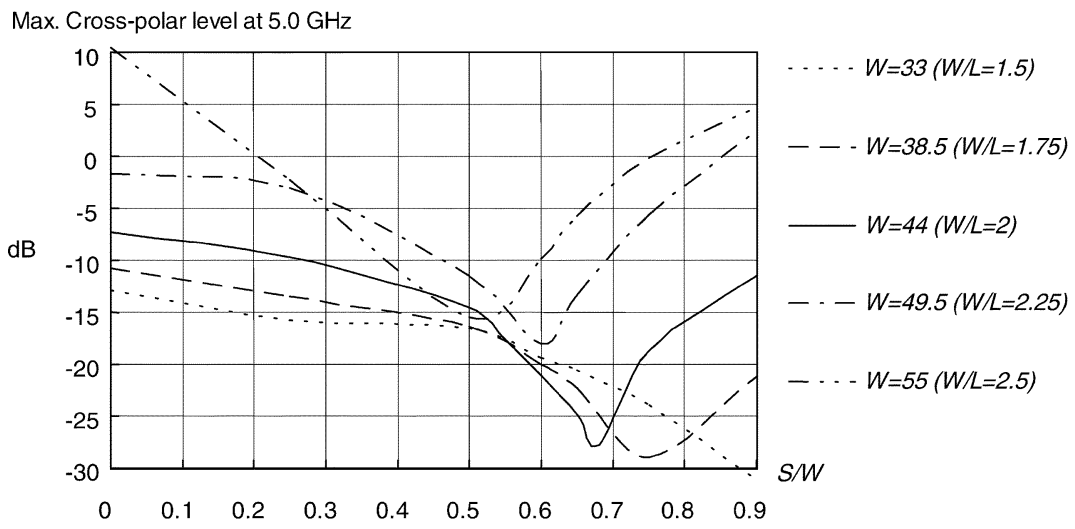

Fig. 8. Parametric studies: simulated results of maximum cross-polar level versus $S / W$.

are $L=22 \mathrm{~mm}$ and $H=6 \mathrm{~mm}$. In addition, parameters such as $a, b, d$, and $Z_{1}$ are slightly adjusted, if necessary, to maintain the wide impedance bandwidth characteristic.

\section{A. Antenna Gain}

By employing the proposed twin-coupling design, especially for a wider patch with $W / L>1.5$, we find that without reducing the impedance bandwidth, there are noticeable improvements in gain as well as the gain bandwidth. Fig. 7 describes the maximum gain verses $S / W$ for different patch width $W$. We can see the maximum gain of a patch is achieved when $S$ is around $0.5 \mathrm{~W}-0.7 \mathrm{~W}$. Moreover, the wider the patch width $W$, the higher the maximum gain can be achieved. Table III summarizes such observations. However, the tradeoff of using wider patch will be a higher cross-polar radiation level are discussed later.

\section{B. Cross-Polar Radiation}

Fig. 8 shows the maximum value of cross-polar level, in the $H$-plane at $5 \mathrm{GHz}$, with different values of $S / W$. It is obvious to see that a wider patch will give a higher cross-polar level. Furthermore, for each patch employing the proposed design (i.e.,
$S>0$ ), the lowest cross-polar level can be achieved when $S$ equals half-wavelength. For example, when $W=44 \mathrm{~mm}$, the lowest cross-polar level of $-27.72 \mathrm{~dB}$ occurs when $S=0.68 \mathrm{~W}$ (i.e., $S=30 \mathrm{~mm}$ ), which is half-wavelength of $5 \mathrm{GHz}$. Table IV summaries such noticeable results.

Fig. 9 shows the maximum value of the cross-polar level for different $S$ across frequency of patch with $W=44 \mathrm{~mm}$. In this figure, a local minimum is clearly observed at the lower band; for example, for the curve of $S=0.75 \mathrm{~W}(33 \mathrm{~mm})$, the minima is find at frequency about $4.5 \mathrm{GHz}$, so $S=0.495 \lambda_{4.5 \mathrm{GHz}}$. Such phenomenon becomes less obvious for $S$ smaller than 0.68 $\mathrm{W}$, but suppression in cross-polar level can still be observed. It is important to notice that although we can have sharp local minima of cross-polar level in the lower region of the operating bandwidth, the tradeoff is a relative higher level in the upper region. Therefore, we need to optimize the overall performance by choosing an appropriate value of $S$. In addition to the goals of high gain and wideband, we have chosen one set of parameters, $W=44 \mathrm{~mm}(W / L=2.0)$ and $S=28.6 \mathrm{~mm}(S / W=0.65)$, for real performance testing. The experiments were already discussed in Section II with measurement results shown in Section III. 
TABLE IV

PARAmetric Studies: Summary of the Simulated Results of the Cross-Polar Level of THe Proposed DesigN

\begin{tabular}{c|c|c|c|c|c}
\hline W $/ M M$ & 33 & 38.5 & 44 & 49.5 & 55 \\
\hline Lowest cross-polar level & $-31 \mathrm{~dB}$ & $-29 \mathrm{~dB}$ & $-27.72 \mathrm{~dB}$ & $-18 \mathrm{~dB}$ & $-15.4 \mathrm{~dB}$ \\
\hline at $S / W$ & 0.9 & 0.75 & 0.6818 & 0.6 & 0.5 \\
\hline \multirow{2}{*}{ i.e. $S$ equals to } & $29.7 \mathrm{~mm}$ & $28.875 \mathrm{~mm}$ & $30 \mathrm{~mm}$ & $29.7 \mathrm{~mm}$ & 27.5 \\
& $(0.495 \lambda)$ & $(0.48 \lambda)$ & $(0.5 \lambda)$ & $(0.495 \lambda)$ & $(0.458 \lambda)$ \\
\hline
\end{tabular}

Max.Cross-polar level of patch $W=44$

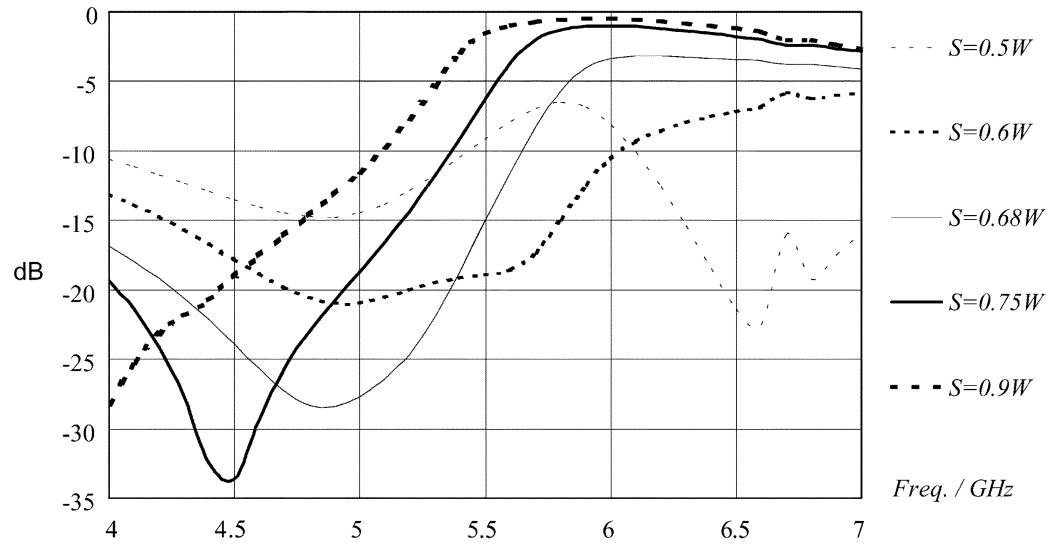

Fig. 9. Parametric studies: simulated results of maximum cross-polar level versus frequency.

\section{Discussions}

The proposed twin- $L$-coupled structure can simultaneously tackle the narrow-bandwidth and low-gain problems of patch antenna for the following reasons. First, as the two in-phased $L$-probes excite the same $\mathrm{TM}_{01}$ mode for radiation, the higherorder modes of $\mathrm{TM}_{10}, \mathrm{TM}_{30}$, etc., excited by each probe, will cancel each other due to their opposite directions. The end-fire higher-order mode $\mathrm{TM}_{20}$ is weakly excited, since the positions of the two probes are located near the $E$-field minimum of this mode. Other end-fire higher-order modes are insignificant as their resonant frequencies are further away. Second, due to the array effect, the radiation contributed by the vertical parts of the two $L$-probes will interact each other. When they are suitably separated, the cross-polarization at angles close to the broadside direction of the patch can be significantly suppressed. Hence, the antenna gain can be effectively improved across the operating bandwidth. Third, the twin-feed structure allows a wide patch to be well excited and, along with the thick substrate with low dielectric constant, high antenna gain is definitely expected. Finally, the $L$-probe coupling technique [11], [12] can easily provide the important wide-band performance.

\section{CONCLUSION}

A dual-feed technique is introduced to the wide-band $L$-probe coupled patch antenna to further enhance its performance. The proposed design, namely a twin- $L$-probe coupled patch antenna, is a one-layered single patch with simultaneously high-gain and wide-band features. High gain of $10 \mathrm{dBi}$ is achieved across the wide operating band of $25 \%(\mathrm{SWR} \leq 1.5)$ since the 1 -dB-gain bandwidth is $26 \%$. Measured results have been verified by a series of simulation studies. Parametric studies have also been performed using Zealand-IE3D, effects of varying the aspect ratio and probe-to-probe distance have been investigated in details, which can provide design guideline for antenna designers. Antenna array can be designed using the proposed antenna element to further increase the gain, which is suitable for mobile communication applications such as base station antenna and other high-gain antenna designs.

\section{ACKNOWLEDGMENT}

The authors would like to thank the anonymous reviewers of this manuscript for their constructive comments and suggestions.

\section{REFERENCES}

[1] J. R. James and P. S. Hall, "Characteristics of microstrip patch antennas and some methods of improving frequency agility and bandwidth," in Handbook of Microstrip Antennas. London, U.K.: Peregrinus, 1989, ch. 3 .

[2] I. J. Bahl and P. Bhartia, Microstrip Antennas. Norwood, MA: Artech House, 1980.

[3] E. Chang, S. A. Long, and W. F. Richards, "Experimental investigation of electrically thick rectangular microstrip antennas," IEEE Trans. Antennas Propag., vol. AP-34, no. 6, pp. 767-772, Jun. 1986.

[4] D. M. Pozar and B. Kaufman, "Increasing the bandwidth of a microstrip antenna by proximity coupling," Electron. Lett., vol. 23, pp. 368-369, 1987.

[5] C. Wood, "Improved bandwidth of microstrip antennas using parasitic elements," Proc. IEE-Microw., Antennas, Propagat., vol. 127, pp. 231-234, 1980.

[6] G. Kumar and K. C. Gupta, "Nonradiating edges and four edges gap-coupled multiple resonator broad-band microstrip antennas," IEEE Trans. Antennas Propag., vol. AP-33, no. 2, pp. 173-178, Feb. 1985.

[7] T. M. Au, K. F. Tong, and K. M. Luk, "Characteristics of aperture-coupled coplanar microstrip subarrays," in Proc. IEE-Microw., Antennas, Propagat., vol. 144, 1997, pp. 137-140.

[8] R. B. Waterhouse, "Design of probe-fed stacked patches," IEEE Trans Antennas Propag., vol. 47, no. 11, pp. 1780-1784, Nov. 1999.

[9] P. S. Hall, "Probe compensation in thick microstrip patches," Electron. Lett., vol. 23, pp. 606-607, 1987. 
[10] K. F. Lee, K. M. Luk, K. F. Tong, S. M. Shum, T. Huynh, and R. Q. Lee, "Experimental and simulation studies of the coaxially fed U-slot rectangular patch antenna," in Proc. IEE - Microw., Antennas, Propagat., vol. 144, 1997, pp. 354-358.

[11] K. M. Luk, C. L. Mak, Y. L. Chow, and K. F. Lee, "Broadband microstrip patch antenna," Electron. Lett., vol. 34, pp. 1442-1443, 1998.

[12] C. L. Mak, K. M. Luk, and K. F. Lee, "Experimental study of a microstrip patch antenna with an $L$-shaped probe," IEEE Trans. Antennas Propag., vol. 48, no. 5, pp. 777-783, May 2000.

[13] H. Y. Yang and N. G. Alexopoulous, "Gain enhancement methods for printed circuit antennas through multiple superstrates," IEEE Trans. Antennas Propag., vol. AP-35, no. 7, pp. 860-863, Jul. 1987.

[14] - "Generation of nearly hemispherical and high gain azimuthally symmetric patterns with printed circuit antennas," IEEE Trans. Antennas Propag., vol. AP-35, no. 8, pp. 972-977, Aug. 1987.

[15] R. Q. Lee and K. F. Lee, "Experimental study of the two-layer electromagnetically coupled rectangular patch antenna," IEEE Trans. Antennas Propag., vol. 38, no. 8, pp. 1298-1302, Aug. 1990.

[16] R. Q. Lee, R. Acosta, and K. F. Lee, "Radiation characteristics of microstrip arrays with parasitic elements," Electron. Lett., vol. 23, pp. 835-837, 1987.

[17] R. E. Munson, "Conformal microstrip antennas and microstrip phased arrays," IEEE Trans. Antennas Propag., vol. AP-22, no. 1, pp. 74-78, Jan. 1974.

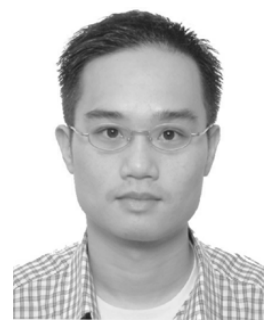

Chi-Lun Mak (M'02) was born in Hong Kong in 1974. He received the B.Eng. (first class honors) and $\mathrm{Ph} . \mathrm{D}$. degrees in electronic engineering from the City University of Hong Kong, Hong Kong, in 1997 and 2001, respectively.

He visited the Department of Electrical Engineering, City University of Hong Kong, in the summer of 1999 as a Visiting Research Scholar. He was a Research Assistant/Senior Research Assistant with the Wireless Communications Research Centre (RCW), University of Missouri, from 2000 to 2001. He joined the Technical Services Division (TSD), Hong Kong Police Force, as a Police Inspector (Specialist-Radio Frequency) in 2001. In late 2002, he moved back to the Department of Electronic Engineering, City University of Hong Kong, as a Research Fellow. He has been an Antenna Engineer with the Hong Kong Applied Science and Technology Research Institute Company Limited (ASTRI) since September 2004. He has authored one book chapter in Microstrip Antennas, Broadband in an Encyclopedia of RF and Microwave Engineering, edited by K. Chang (Wiley: New York, in press), 13 journal articles, and 15 conference papers. He holds two patents on an invention from two countries, including the United States and China. His research interests include the design of microstrip and planar antennas, microwave theory, and applied electromagnetics.

Dr. Mak currently is the Treasurer and Web Master of the IEEE (Hong Kong) AP/MTT joint chapter. He was the Technical Program Chairman of the 4th/5th IEEE (Hong Kong) AP/MTT Post-Graduate Conference in 2003 (Hong Kong)/2004(Macau). He won two First Prizes including in the IEEE (Region 10) and the IEEE (Hong Kong) Postgraduate Student Paper Contest for 1999. He also received the Sir Edward Youde Memorial Fellowship in 2000, presented by the Sir Edward Youde Memorial Fund Council, Hong Kong. He is also listed in Marquis Who's Who in the World.

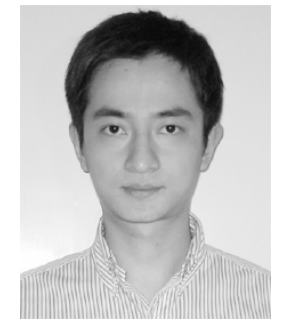

Hang Wong (M'02) received the B.Eng. and M.Phil. degrees in electronic engineering from the City University of Hong Kong, Hong Kong, in 1999 and 2002, respectively, where he is currently working toward the Ph.D. degree.

Since June 2002, he has been an Assistant Engineer with the Wireless Communications Research Centre, City University of Hong Kong, and has been responsible for patch antenna design.

Mr. Wong won a Certificate of Merit at the 2001 Postgraduate Conference presented by the IEEE Hong Kong Section Joint Chapter on MTT/AP/LEOS. He was awarded the second prize in the 2002 Postgraduate Student Paper Content presented by the IEEE Hong Kong chapter and was awarded the Outstanding Research Thesis Award from the City University of Hong Kong in 2002.

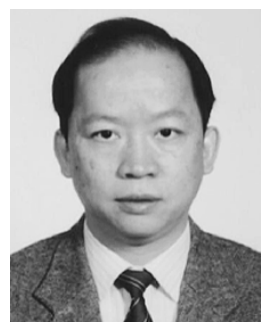

Kwai-Man Luk (M'79-SM'94-F'03) was born and educated in Hong Kong. He received the B.Sc. degree in engineering and the Ph.D. degree in electrical engineering from The University of Hong Kong, Hong Kong, in 1981 and 1985, respectively.

He joined the Department of Electronic Engineering, City University of Hong Kong, in 1985 as a Lecturer. Two years later, he moved to the Department of Electronic Engineering, The Chinese University of Hong Kong, where he spent four years. He returned to the City University of Hong Kong in 1992 and he currently is a Chair Professor and Head of the Department of Electronic Engineering. He has successfully supervised over ten Ph.D. students. Most have achieved their distinguished careers in Hong Kong, Singapore, Japan, and the United States. He is the author of one edited book, five research book chapters, over 200 journal papers, and 140 conference papers. He was recently awarded one U.S. patent and five Chinese patents on the design of a wide-band patch antenna with an $L$-shaped probe. His recent research interests include the design of patch, planar, and dielectric resonator antennas; microwave and antenna measurements; and computational electromagnetics.

Dr. Luk was the Technical Program Chairperson of the Progress in Electromagnetics Research Symposium (PIERS'97), held in Hong Kong in January 1997, and the General Vice-Chairperson of the 1997 Asia-Pacific Microwave Conference, held in Hong Kong in December 1997. He received an international best paper award, the Japan Microwave Prize, at the 1994 Asia Pacific Microwave Conference, held in Chiba, Japan, in December 1994. He was awarded the very competitive Croucher Foundation Senior Research Fellow in Hong Kong in 2000. He received the Applied Research Excellence Award from the City University of Hong Kong in 2001. He is a Fellow of the Chinese Institute of Electronics; a Fellow of the Institution of Electrical Engineers (IEE), U.K.; and a Member of the Electromagnetics Academy, U.S. 